Article

\title{
Seasonal Microbial Population Shifts in a Bioremediation System Treating Metal and Sulfate-Rich Seepage
}

\author{
Susan A. Baldwin ${ }^{1, *}$, Al Mattes ${ }^{2}$, Maryam Rezadehbashi ${ }^{1}$ and Jon Taylor ${ }^{1}$ \\ 1 Chemical and Biological Engineering, University of British Columbia, 2360 East Mall, Vancouver, \\ BC V6T 1Z3, Canada; maryamdehbashi@gmail.com (M.R.); jon.cr.taylor@gmail.com (J.T.) \\ 2 NatureWorks Remediation Corporation, Rossland, BC VOG 1YO, Canada; a1g7m13@gmail.com \\ * Correspondence: sbaldwin@mail.ubc.ca; Tel.: +1-604-822-1973
}

Academic Editor: Karen Hudson-Edwards

Received: 1 February 2016; Accepted: 1 April 2016; Published: 12 April 2016

\begin{abstract}
Biochemical reactors (BCRs) using complex organics for bioremediation of mine-influenced water must operate successfully year round. In cold climates, where many mines in Canada are located, survival of the important microorganisms through the winter months is a concern. In this work, broad phylogenetic surveys, using metagenomics, of the microbial populations in pulp mill biosolids used to remediate metal leachate containing $\mathrm{As}, \mathrm{Zn}, \mathrm{Cd}$ and sulfate were performed to see if the types of microorganisms present changed over the seasons of one year (August 2008 to July 2009). Despite temperature variations between 0 and $17^{\circ} \mathrm{C}$ the overall structure of the microbial population was fairly consistent. A cyclical pattern in relative abundance was detected in certain taxa. These included fermenter-related groups, which were out of phase with other taxa such as Desulfobulbus that represented potential consumers of fermentation byproducts. Sulfate-reducers in the BCR biosolids were closely related to psychrotolerant species. Temperature was not a factor that shaped the microbial population structure within the BCR biosolids. Kinetics of organic matter degradation by these microbes and the rate of supply of organic carbon to sulfate-reducers would likely affect the metal removal rates at different temperatures.
\end{abstract}

Keywords: biochemical reactors; BCR; metals; mine-influenced water; microbial ecology; metagenomics; sulfate-reducing bacteria

\section{Introduction}

Seepage from mine and mineral processing waste containing high concentrations of metals presents a huge challenge to the mining industry as many sites face treatment in perpetuity [1]. To keep costs low, it is attractive to apply, at the location of seepages, so-called passive or semi-passive treatment systems that depend on natural geochemical and microbiological processes [2]. For metal removal, these often take the form of sub-surface flow anaerobic composting bioreactors that are referred to as biochemical reactors (BCRs) by mine bioremediation practitioners [3]. Typically, a naturally sourced or industrially derived waste organic material is used as the carbon source for supporting microbial activity. A cover is provided to exclude oxygen infiltration and to encourage the growth of hydrolytic and fermentative microorganisms that provide low molecular weight carbon compounds for anaerobic sulfate- and metal-reducing bacteria. Sulfate-reducing bacteria are key microbes for successful performance of BCRs since sulfate is present in many mine seepage streams and sulfate-reduction produces sulfide that combines with many metal cations to form sparingly soluble metal sulfides [4]. Much heuristic knowledge is available from practitioners on how to design and operate such systems successfully, but many actual operations do not live up to expectations and regulatory requirements 
cannot be met [5]. This is due to, in part, difficulty in monitoring the BCR environment to find out how conditions change with seasons and as the bioreactor ages.

Since complex organic matter, containing mostly ligno-cellulosic chemical compounds, is used in BCRs, multiple biochemical pathways within a degradation chain are involved in decomposition and carbon cycling, which are performed by a consortium of microbes [6,7]. Microbial population composition is sensitive to environmental variables such as temperature, $\mathrm{pH}$, dissolved oxygen, conductivity, oxidizing/reducing conditions, presence of different chemical constituents and the nature of the carbon source(s), which may vary widely over the seasons [8-10]. Temperature variations, in particular, are great in Northern climes, such as in Canada, where many mines are located, and may influence the effectiveness of passive treatment [11]. Depending on which microbial communities are cold adapted, the metabolic processes taking place within BCRs might be different in the winter months than at warmer times of the year [12]. Successful metal removal is a balance between providing sufficient fermentation products as electron donors and the rate of sulfate-reduction. Changing temperatures and seasonally driven geochemical shifts may influence the activities of microbes within these functional groups differently. Sulfate-reducers are the most important carbon mineralizers in ocean sediments, including permanently cold regions of the Arctic and Antarctic where both mesophilic and psychrophilic species abound [13-16]. It is unknown if psychrophilic sulfate-reducers would be present in BCRs during the winter months. For example, no distinct sulfate-reducer populations were found during the winter and summer in a natural salt marsh [17], and it was hypothesized that psychrophiles do not grow fast enough to reach significant numbers in the cold months or cannot survive the warmer months. Some researchers have argued that there is a population response to temperature variations but not a change in population composition with respect to temperature [18]. Microbial metabolisms are expected to slow with decreasing temperature due to the Arrhenius relationship [14], and this might result in water chemistry changes. Seasonal changes in microbial population composition in mine-influenced water treatment BCRs have not been charted previously, and it was the objective of this work to discover if there are temporal shifts that might be different for some taxonomic groups versus others. Knowledge of the variation in metabolic potential with season will inform practitioners of interventions or amendments that they can implement to improve performance.

The BCR chosen for this study was located in southern British Columbia. This BCR had been operating for approximately 10 years and successfully removed arsenic, zinc, cadmium and sulfate using an organic matrix consisting of pulp and paper mill biosolids [19-21]. Microbial population composition was monitored over a period of one year from August 2008 to July 2009 using pulp and paper mill biosolids passive samplers submerged into the pore water of the bioreactor.

\section{Results}

\subsection{Pore Water Chemistry Surrounding the Biosolids Samples}

The geochemical environment of the pore water in close proximity to the biosolids was consistent for the duration of the experiment (Table S1). Except for temperature, which varied from 0 to $17^{\circ} \mathrm{C}$, other environmental conditions within the bioreactor pore water were fairly constant, such as $\mathrm{pH}(6.9 \pm 0.3)$, nitrate $(1.19 \pm 0.58 \mathrm{mg} / \mathrm{L})$, ammonia $(80.1 \pm 8.83 \mathrm{mg} / \mathrm{L})$ and sulfate $(416 \pm 63 \mathrm{mg} / \mathrm{L})$. The oxidation-reduction potential (ORP) dropped below zero only during the warmer summer months of August 2008, June and July 2009. The ORP readings failed to stabilize and different measurements were obtained when alternate meters and probes were used. Low levels of dissolved oxygen were detected. Dissolved oxygen in the lysimeter water was higher in the colder months of January, February and March 2009. Similar levels of dissolved oxygen were measured in the warmer month of June 2009. 


\subsection{Organic Material Characteristics}

The biosolids matrix from all months contained an average of $11.4 \pm 0.8 \mathrm{wt} \%$ total organic carbon (TOC), with little variation among samples despite their different exposure periods (Table S2). Material within the three Rock-Eval-6 fractions S1, S2 and S3 was detected. According to previous Rock-Eval-6 analyses of various model organic compounds, fraction $\mathrm{S1}$ is produced from pyrolysis of low molecular weight ( $<500 \mathrm{Da}$ ) molecules, S2 from labile organic polymers such as lipids and some carbohydrates, and S3 from more recalcitrant ligno-cellulosic material [22]. Total pyrolysable carbon (PC) (the sum of fractions S1, S2 and S3) normalized to the TOC averaged $47.8 \mathrm{wt} \%$ with a standard deviation of only 3.9\%. A small spike in PC/TOC was seen in the February, March and April samples. There were no detectable overall trends suggesting the depletion of any of these fractions (S1, S2 and S3) over time. Taken together, the pore water and solid chemistry analyses depict a fairly consistent chemical environment for the duration of the experiment, with temperature being the most variable environmental factor.

\subsection{Overall Microbial Population Composition}

A total of 49112 high quality sequences for the V6-V8 variable region of the small subunit ribosomal ribonucleic acid (SSU rRNA) gene were obtained from the 11 monthly samples that were analyzed. It was not possible to collect a sample in December due to the presence of deep snow. The number of reads per sample varied from 1616 (for August 2008) to 7366 (for September 2008) with an average of 4665 reads per sample. Sequences were binned into $179295 \%$ similarity cut-off operational taxonomic units (OTUs). Rarefaction to assess diversity using indices chao-1 [23] and phylogenetic diversity (PD) using the whole tree [24] revealed that the microbial populations in the initial months (August, September and November 2008) were the least diverse (Figure S1). More diverse populations were observed in January, March and April of 2009.

Overall, Bacteroidetes was the most prevalent Phylum represented in the samples (33\% of all reads), followed by Firmicutes (24\%), Proteobacteria (14\%), Spirochaetes (7.3\%), Euryarchaeota (6.6\%), Fibrobacteres (5.9\%) and Actinobacteria (1.9\%). The Euryarchaeota included methanogens that produce methane from fermentation by-products acetate, formate, $\mathrm{H}_{2}$ and $\mathrm{CO}_{2}$ [25]. Other notable phyla present included the Candidate Division OP11 (1.2\%), of which there are no cultured representatives. The purpose of our study was to examine temporal variation over several seasons with wide temperature shifts of the broad functional groups and their members.

Despite the large temperature fluctuations throughout the year, the microbial population compositions of the samples were very similar to each other (i.e., Order shown in Figure 1). Most methanogens (94\% of all Archaea-related sequences) were classified into three Orders: the hydrogenotrophic Methanobacteriales, the slightly more metabolically versatile Methanomicrobiales that can utilize formate and methanol in addition to $\mathrm{H}_{2}$ for methane production, and the metabolically versatile Methanosarcinales that also metabolize acetate and C-1 compounds. Methanogens were particularly prevalent in June mostly due to a flourish in Methanocorpusculum sp. Most (78\%) of the Bacteroidetes and Firmicutes were classified into only three Orders. The Proteobacteria were more diverse than any of the other Phyla. Six of the most prevalent Orders are shown in Figure 1, which comprise $74 \%$ all reads assigned to the Proteobacteria. Sequences related to sulfate-reducing bacteria Orders (Desulfobacteriales and Desulfovibrionales) appeared only in the 2009 samples. When the phylogenetic composition of the microbial populations found in the various months were compared with each other using UniFrac determined distances and principal co-ordinate analysis (Figure 2), they formed two general clusters. The June microbial population stood out due to the prevalent methanogens present at that time. The October sample was distinguished by prevalence of OP11. 


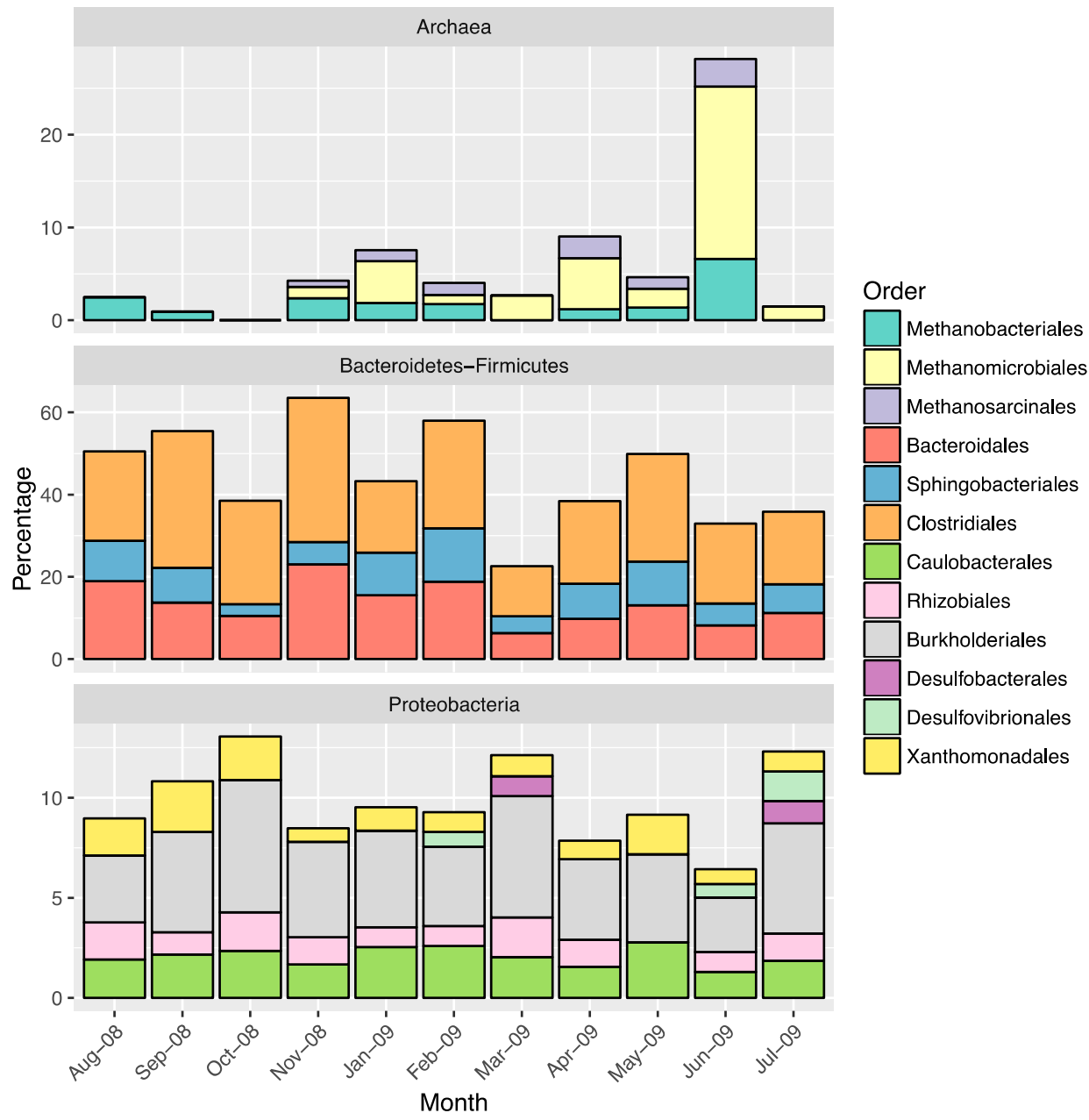

Figure 1. Relative abundance of the major Orders in the biochemical reactor (BCR) biosolids over the study period.

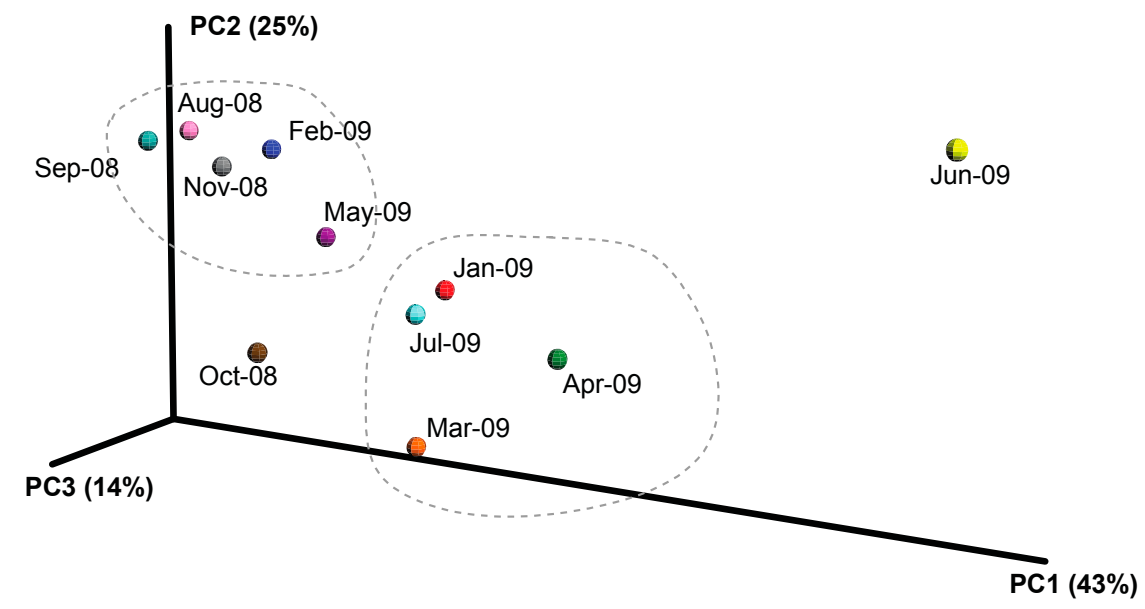

Figure 2. Principle co-ordinate plot comparing the microbial population compositions in the various months.

A more detailed analysis of the taxonomy of microbes present was done by counting the number of sequences assigned to taxa at the genus level (Figures S2 and S3 in the Supplemental Information). 
Genus-level OTUs were used to explore effects of environmental variables temperature $(T)$, dissolved oxygen (DO), time, iron concentration (Fe) and the ratio of pyrolysable carbon (PC) to total organic carbon (TOC) on microbial population composition (Figure S4). The only statistically significant trend observed was a shift in the microbial population structure over time for the duration of the experiment.

A correlation analysis revealed that co-occurring genus-level taxa grouped together into two highly correlated clusters that were negatively correlated with each other (Figure S5). Highly correlated taxa in one cluster (on the right-hand side of Figure S5) were classified as Methanosphaerula (methanogen), Desulfobulbus and Desulfovibrio (sulfate-reducers), Spirochaetes C-2, Candidate Division OP11 and Prolixibacter. The relative (to the total for each OTU) read counts for six of these OTUs in each monthly sample follow similar patterns (Figure 3a) in that they peak in October, January, March, April and July. These time points coincided with the peaks seen in the diversity metrics, and were grouped together in the principle co-ordinate analysis (Figure 2). In contrast, the OTUs in the other highly correlated cluster (left hand side of Figure S5), which were mainly assigned to genera of species involved in fermentation (i.e., Acidaminococcus, Saccharofermentans, Fibrobacter and Paludibacter), peaked in alternate months of November, February, and May (Figure 3b). These latter three months were similar in overall microbial population structure (Figure 2).

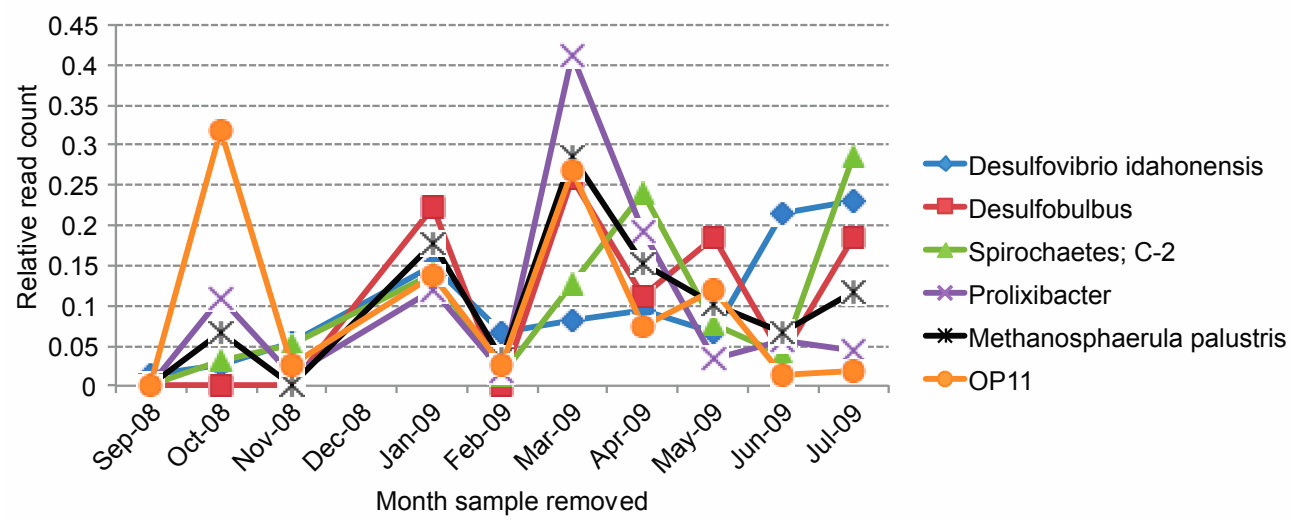

(a)

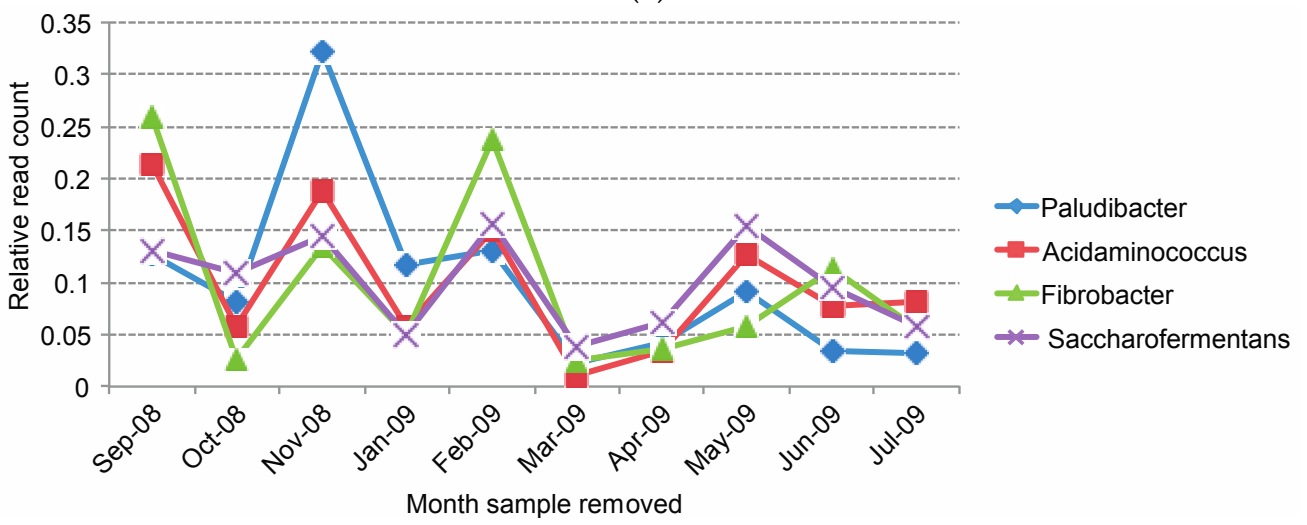

(b)

Figure 3. Plots of relative (to the total read count for that OTU) prevalence of co-occurring taxa in the two negatively correlated clusters (a) and (b).

\subsection{Diversity of Sulfate-Reducing Bacteria}

Sulfate-reducing bacteria are an important functional group for these BCRs since they produce sulfide and promote metal precipitation. They were not a major component of the total population as the percentage of reads assigned to all of the known sulfate-reducing bacteria taxa was small at approximately $2 \%$. They were not present in the original biosolids, but they increased in prevalence 
over time (Figure 4) indicating that the environment in the BCR pore water and supply of fermentation products were suitable for their growth. In addition to the two major Orders mentioned previously, sulfate-reducers were also classified in the Orders Desulfarculales and Desulfuromonadales (Figure S6). Some Deltaproteobacteria-related OTUs were not closely related to any known cultured species and were classified into environmental groups, notably Sh765B-TzT-29 (OTU1073 in Figure S6) and GR-WP33-30 (OTU 4252 in Figure S6).

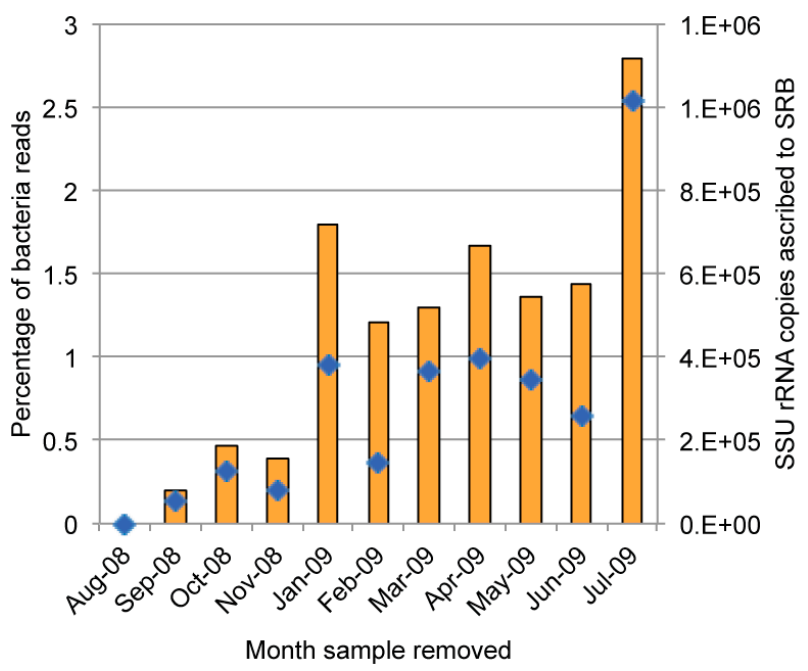

Figure 4. Percentage of bacterial SSU rRNA amplicon sequences assigned to known sulfate-reducing bacteria taxonomic groups in each month (orange bars and left-hand side $y$-axis). Number of bacterial SSU rRNA gene copies ascribed to sulfate-reducing bacteria (blue diamonds and right-hand side $y$-axis).

\subsection{Quantification of Bacterial Genes}

Results from sequencing of SSU rRNA amplicons provided valuable information on relative abundance of microbial taxa within each of the samples. To compare quantitative differences in the microbial populations, bacterial SSU rRNA marker genes were quantified using quantitative polymerase chain reaction (qPCR) assays. Abundance of bacterial SSU rRNA was three fold less in Winter 2009 (February) than in Fall 2008 (September/October) (Figure 5). Bacterial abundance increased in the Spring 2009 samples. The greatest abundance of bacteria was observed in July 2009. June was an anomaly in that bacterial gene copies were almost as low as in February.

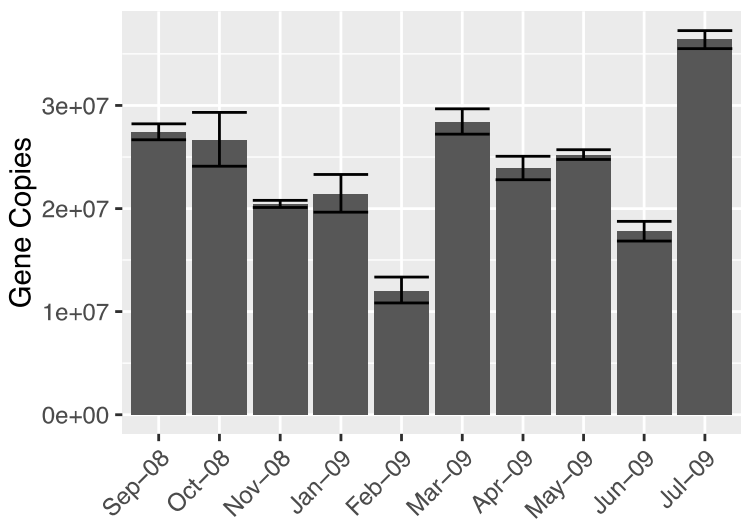

Figure 5. Number of bacterial SSU rRNA gene copies per $0.5 \mathrm{~g}$ of biosolids mixture in each of the monthly samples measured using qPCR. 
The number of SSU rRNA copies potentially from sulfate-reducing bacteria was estimated by multiplying the fraction of bacterial reads assigned to known sulfate-reducing bacteria taxa to the bacterial SSU rRNA copy number found from qPCR. These results give approximations of the absolute abundances of sulfate-reducing bacteria (blue diamonds in Figure 4). The trend indicated a sharp increase in sulfate-reducers in January 2009 followed by a drop in February 2009. Numbers of sulfate-reducers increased again in March 2009 thereafter declining somewhat. Highest abundance, over the experimental period, of sulfate-reducers occurred in July 2009.

\section{Discussion}

\subsection{Environmental Factors Influencing Microbial Population Structure}

Semi-passive remediation systems are expected to operate under a wide range of temperatures since they are located often in remote areas where energy for heating the influent water is not available. Water has a relatively high heat capacity and requirements for heating would subjugate the advantages of passive treatment, one of which is elimination or minimization of operating costs. Many mines in British Columbia are located at high elevations and at northern latitudes, where it is particularly challenging to make biological treatment effective in the cold winter months. Kinetics of biological reactions and microbial growth are influenced by temperature according to a consistent expression that takes into account Arrhenius-type rate dependency on temperature and protein denaturation at below and above optimum temperatures for maximum growth [26]. It is thought that growth within different temperature regimes (psychrophilic, mesophilic and thermophilic) is determined by adaptation and not by taxonomy [26]. Our work supports this notion in that the microbial population composition of the bioreactor did not vary with temperature in a statistically significant way. In the early months, from August till November 2008, few sulfate-reducers were present despite high total bacteria SSU rRNA gene copy numbers. Since the biosolids did not come from a high-sulfate concentration environment, they initially did not contain sulfate-reducing bacteria. Thus, as sulfate-reducers present in the BCR pore water took time to colonize the biosolids, their abundance was low. Sulfate-reducers in the biosolids appear not to have been inhibited by low temperatures, since their relative abundance, and estimated absolute abundance, increased sharply in the January 2009 sample and for most of the subsequent months they constituted around $1 \%-2 \%$ of the total population. From January onwards the relative abundance of sulfate-reducers approximately tracked total bacterial abundance. For instance, in July when the total bacteria numbers were highest, relative abundance of sulfate-reducers was also highest. Even though the composition of the microbial community did not change with temperature, temperature was still expected to influence activity. Indeed, the overall abundance of bacteria appeared to decrease in the colder months based on the lower SSU rRNA gene copies measured in January and February 2009. Although the relative abundance of sulfate-reducers remained similar from January till June, their estimated absolute abundance was lower in February due to the lower overall bacterial abundance. Thus, lower overall abundance of microorganisms and decreased metabolic activity are likely explanations for reduced performance of the BCR in winter rather than shifts in the types of microorganisms present.

Duration of submersion in the BCR was the only statistically significant effect on the microbial population composition. The increase in relative abundance of sulfate-reducers from August to January was attributed to their colonization of the biosolids since they were not present in the original material. An overall decline in relative abundance of the fermenter-related taxa was observed (e.g., Firmicutes genera Acidaminococcus, Saccharofermentans, Anaerofilum in Figure S2). This was coupled with an increase in relative abundance of some other taxa such as the Bacteroidetes environmental group vadinHA17 and the Spirochaetes genus Treponema over time. No changes in the composition of the organic matter according to Rock-Eval-6 analysis were detected. A more detailed and complete analysis might have revealed changes in carbon source availability over time. Environmental groups, such as vadinHA17, represent microbes whose metabolic capabilities are unknown. Since vadinHA17-related 
clones or OTUs are found in many anaerobic digesters, we can only hypothesize that they have a metabolic advantage in degrading complex recalcitrant organic compounds by some unknown pathway. Many other factors not measured in the current study might play a role in determining relative abundance of taxa in bioreactors, such as antagonistic interactions between microbes [27]. Some taxa produce inhibitory compounds that reduce the relative abundance of other taxa sensitive to these compounds. Thus, biotic as well as abiotic factors shape microbial population structure.

\subsection{Possible Functional Roles for the Taxonomic Groups Found in the BCR Biosolids}

It was not surprising that many different types of microorganisms were found since complex organic matter degradation involves multiple steps and a mixed population of microorganisms (Figure 6) [28]. Since complex carbohydrates such as cellulose were likely important sources of organic carbon, cellulose-degraders were expected. Some cellulose-degrading bacteria are also capable of fermentation. Many other types of fermenters that produce fermentation by-products; $\mathrm{CO}_{2}, \mathrm{H}_{2}$, organic acids, alcohols, acetate and formate were also expected to comprise a significant fraction of the microbial population. These products, especially propionate and butyrate, fuel syntrophs that broker cellulose degradation with terminal electron acceptor processes such as methanogenesis. When sulfate is present, as it is in the BCR, sulfate-reducers utilize fermentation products for growth and energy. The purpose of this study was to chart the relative abundance of the taxa associated with each of the broad functional processes taking place in the BCR (the boxes in Figure 6).

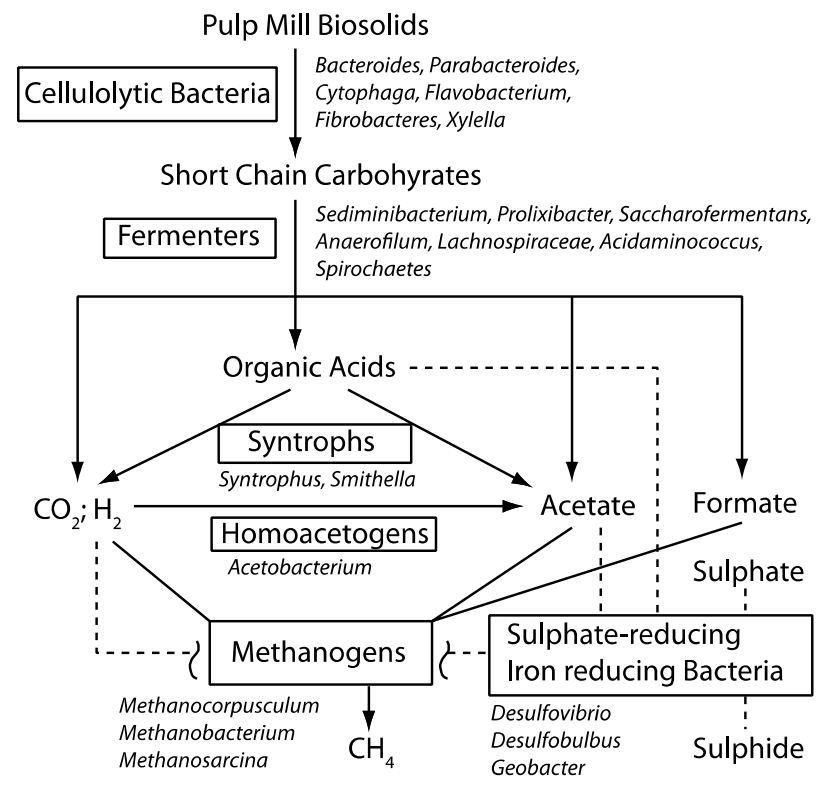

Figure 6. Schematic of the main steps speculated to take place in the microbial degradation of biosolids in the BCR. Prevalent genus-level taxa found in this study potentially involved in each step are listed in italics.

Identification of taxa based on a short fragment of their SSU rRNA gene classifies them to the genus level (as in Figures S2 and S3). Although not definitive, we can speculate on their possible functional roles based on what is known about species classified within the same genera. It must be born in mind that even species that are very closely related genetically may not have exactly the same phenotype. Still a notion of what metabolic potential the various taxonomic groups might have in the BCR can be garnered from what is known about closely related cultured species and from the functional genes within genomes of those species that have been fully sequenced. 


\subsubsection{Cellulose-Degrading Bacteria}

Predominant Bacteroides and Parabacteroides present within the Bacteroidales Order were possible cellulose-degraders since species within these genera have many glycosyl hydrolases that enable them to breakdown complex carbohydrates into simple sugars [29]. They are metabolically versatile depending on nutrient availability, and can also ferment carbohydrates to fatty acids. Cytophaga and Flavobacterium genera found in the biosolids have species that degrade plant-related organic matter [30]. The unclassified Porphyromonadaceae found in the BCR were closely related to environmental clones from other bioreactors treating complex carbohydrates (e.g., those represented by accession numbers HQ602914, KP233810, FJ675662, GQ135926 in the NCBI nucleotide database) suggesting that they might be involved in breakdown of complex carbohydrates. Other taxonomic groups found in the BCR biosolids that represent possible hydrolytic microbes were the Actinobacteria, even though they are usually aerobes [31], and the Fibrobacteres [32]. Interestingly, the predominant Actinobacteria genera represent halophilic species isolated from cold marine environments [33,34]. Genera associated with plant matter degradation were present also among the Proteobacteria phylum (e.g., Xylella [35]).

\subsubsection{Fermenters}

Sediminibacterium and Prolixibacter, within the Sphingobacteriales Order, were possible fermenter genera growing on the products of carbohydrate hydrolysis [36]. There is only one known species of Prolixibacter that co-occurred with metal-reducing microorganisms on a microbial fuel cell anode [36]. Most of the genera found within the Clostridiales Order were fermentative organisms that grow on simple sugars and produce organic acids such as lactate, acetate, formate and butyrate (Saccharofermentans, Anaerofilum, Lachnospiraceae) [37,38]. The most highly prevalent genus in the Clostridiales Order was Acidaminococcus, species of which are thought to use amino acids (such as glutamate) exclusively as their carbon source. Other phyla in the BCR possibly constituting fermenter microorganisms were the Spirochaetes. Some species of Spirochaetes are syntrophic with cellulolytic organisms [39], and they are frequently found in sulfate-reducing BCRs [40,41].

\subsubsection{Others}

Acetobacterium found within the Clostridiales Order represents a homoacetogenic genus [42], species of which produce acetate from $\mathrm{H}_{2}$ and $\mathrm{CO}_{2}$ and compete with methanogens (Figure 6). Representatives of syntrophs were found among the rare genera $(<0.1 \%$ relative abundance). The Proteobacteria phylum contains many microorganisms that are important in bioremediation of hydrocarbon as well as metal contaminated environments. Within the Burkholderiales Order, two genera Polaromonas and Aquabacterium that were found in the BCR are frequently associated with hydrocarbon degradation in contaminated soils [43,44]. Another Burkholderiales genus present in the BCR, Acidovorax, includes species capable of arsenite oxidation [45]. Genera within the Rhizobiales Order (e.g., Rhizobium) were closely related to metal-tolerant species that might play a role in metal sequestration $[45,46]$. Genera found within the Caulobacterales Order (Caulobacter and Brevundimonas) are ubiquitous in many different environments. They are oligotrophic and can metabolize aromatic hydrocarbons as well as plant-derived carbohydrates and organic acids [47,48].

The most prevalent sulfate-reducer found in the biosolids, Desulfovibrio idahonensis-related OTU 3235 in Figure S4, was more than 97\% similar to a psychrotolerant sulfate-reducer species, D. arcticus (accession number DQ296030.1), that was isolated from permafrost on the Varandey Peninsula (Barents Sea) [49]. When comparing the Desulfobulbus-related OTU representative sequences from the biosolids to the greengenes database [50] using Blastn, the closest relatives (>96\% similar) were also from metal-contaminated or mine sites [51]. Thus, the sulfate-reducing bacteria found in the BCR and their close relatives also found in metal-rich or cold marine environments may share special adaptations to stressful environments. Many mesophilic sulfate-reducers are present in permanently cold environments $[15,16]$ indicating that they are psychrotolerant and some are active at 
low temperatures [14]. In cold Arctic Ocean sediments, sulfate-reducers are thought to contribute to the majority of carbon cycling [52].

Iron-reducing bacteria were detected in the biosolids (Geobacter), although they were rare $(<0.1 \%)$. Methanogens with the potential to use all the possible available substrates, $\mathrm{CO}_{2}, \mathrm{H}_{2}$, acetate and formate, were present to complete the degradation of organic matter.

\subsection{Co-Occurrence of Taxa in the BCR Biosolids}

The variability of the microbial population structure appeared to be cyclic. In other environments, such as marine, repeatable seasonal patterns in microbial population structure have been observed that were attributed to seasonal nutrient cycling [9]. Lotka-Volterra type cyclical patterns influenced by nutrient availability, or protagonistic or antagonistic biotic factors, might be taking place in the bioreactor. The co-occurrence analysis detected variations in relative abundance of specific genera within two clusters negatively correlated with each other. The taxa in the first cluster have in common that their closest isolate or cultured species relatives are also from metal-rich or hypersaline environments (Accession numbers: AJ582758.1, AJ582755.1, EU156000.1, AY548789.1, AY548775.1) suggesting that they share adaptability to these stressful environments. Representative sequences for the Spirochaetes C-2 and OP11 classified OTUs were not closely related to any isolates or cultured species. Members within the Spirochaetes are core to anaerobic digesters [53] and are known to be syntrophic with methanogens and can outcompete other fermenters, such as Clostridium species [54]. The first environmental clone for OP11 was isolated from the Obsidian Pool in Yellow Stone National Park that is an environment rich in metals and sulfur compounds [55]. OP11-related organisms have been identified at other metal bioremediation sites [56]. Genomic studies of these suggest that they are strict anaerobe fermenters capable of $\mathrm{H}_{2}$ generation. There is evidence that they may provide fermentation products for iron- and sulfate-reducing bacteria. In this cluster, the predominant sulfate-reducers and one type of methanogen co-occur. Both sulfate-reducers and methanogens need low molecular weight carbon sources such as acetate, $\mathrm{H}_{2} / \mathrm{CO}_{2}$, lactate, propionate, and butyrate. It is possible that these are produced by the co-occurring genera: Prolixibacter, OP11 and Spirochaetes C-2.

There are several possible explanations for the alternating variation in relative abundance of genera within these two clusters. One explanation for these two groups of co-occurring microbial taxa being negatively correlated with each other might be due to their trophic interactions. For instance, the taxa within the right-hand side cluster may rely on carbon sources produced by the fermentative bacteria in the left-hand side cluster. Product inhibition of fermenter activity due to accumulation of products when consumers such as sulfate-reducers and methanogens are less prevalent might slow down the growth of fermenter organisms until sulfate-reducers and methanogens, and possibly other members of the first group, consume the fermentation products. Thus, fluctuating carbon source supply as fermentation products are produced and consumed might have contributed to the cyclical sequential relative abundance patterns seen for the major taxa in the BCR biosolids over time. Another explanation might be that these two groups are directly competitive with each other for the same nutrients. The putative fermenters (Prolixibacter, OP11 and Spirochaetes C-2) might be syntrophic with the specific sulfate-reducers and methanogens with which they co-occur giving this cluster of microorganisms an advantage over those in the other cluster. Microorganisms represented by the two clusters might directly compete with each other by secreting antimicrobial compounds that kill or impede the growth of microbes in the other cluster [56]. Most natural microbial populations consist of consortia of co-operating taxa that are constantly competing with each other for resources using a wide variety of strategies [57]. As a result, microbial population structure is dynamic and very rarely static. Outcomes of such interactions can include more or less stable oscillations that occur year after year, as have been seen in marine environments [9], or may include dramatic shifts towards undesirable microbial taxa as has been the case in water treatment bioreactors overcome by filamentous species [58]. Thus, it cannot be assumed that the microbial population structure of BCRs used for metal remediation 
remains consistent over time and factors influencing microbial population dynamics of these systems needs to be further elucidated.

\section{Materials and Methods}

\subsection{Experimental Design}

Fresh biosolids (46.9\% total organic carbon, $\mathrm{pH} 6.7,71.3 \%$ moisture content) from a local pulp mill were mixed with limestone and sand in the same ratios as were used in the BCR during its construction and placed into 12 separate mesh bags. In July 2008, all 12 bags were placed into the lysimeter such that they were about $2 \mathrm{~m}$ below the water surface. This way, the mesh bags and their biosolids contents were bathed in the BCR pore water as it flowed through the lysimeter. Each month, one mesh bag was removed from the $\mathrm{BCR}$, frozen immediately and stored at $-80^{\circ} \mathrm{C}$ until analysis. Therefore, each mesh bag spent a different time period inside the BCR pore water. For example, the mesh bag removed in August 2008 spent one month in the BCR, the bag removed in September 2008 spent two months in the BCR and so on.

\subsection{Chemistry Measurements}

Bioreactor influent and effluent water chemistry were measured bi-weekly [20] and the lysimeter pore water monthly at the same time that a biosolids mesh bag was removed. $\mathrm{pH}$, oxidation-reduction potential (ORP), dissolved oxygen (DO) and temperature were measured in situ with multi-probe field meters according to the manufacturer's instructions (Hach Company, Loveland, CO, USA). Sulfide and ferrous iron were measured immediately upon taking the samples using the methylene blue colorimetric method 4500-S $\mathrm{S}^{2-}$ and the phenanthroline colorimetric method 3500-Fe B, respectively [59]. Ammonium- $\mathrm{N}$, nitrite- $\mathrm{N}$ and nitrate- $\mathrm{N}$ were measured immediately colorimetrically using the salicylate method [60] and methods $4500-\mathrm{NO}_{3}{ }^{-}, \mathrm{NO}_{2}{ }^{-}$[59], respectively. Total and dissolved metals and sulfate (calculated from total $\mathrm{S}$ ) were measured using inductively coupled plasma mass spectrometry (ICP-MS) or inductively coupled plasma atomic emission spectroscopy (ICP-AES) at an industrial laboratory.

\subsection{Characteristics of the Organic Matrix}

The composition of the organic material was estimated using a pyrolysis technique that has been used previously for characterizing soil organic matter [61] and pulp mill biosolids within the BCR [20]. In the Rock-Eval-6 technique, samples are exposed to progressively increasing temperatures, during which hydrocarbon compounds of differing molecular weights are liberated and quantified. The method used for biosolids samples is given in detail elsewhere [20]. Briefly, the so-called S1 and S2 fractions represent hydrocarbons liberated at $300^{\circ} \mathrm{C}$ and when the temperature is increased from $300-650^{\circ} \mathrm{C}$, respectively, and the $\mathrm{S} 3$ fraction is the amount of $\mathrm{CO}_{2}$ evolved during pyrolysis. The sum of these three fractions constitutes the pyrolysable carbon (PC) in $\mathrm{mg} / \mathrm{g}$-solids. This was normalized by the amount of total organic carbon (TOC weight \%) in the sample to quantify the portion of labile and thus potentially bioavailable carbon.

\subsection{Deoxyribonucleic Acid (DNA) Extraction}

Genomic DNA was extracted from the thawed and homogenized mesh bag contents using the MoBio ${ }^{\circledR}$ PowerSoil DNA extraction kit (MoBio Laboratories, Solana Beach, CA, USA) according to the manufacturer's instructions with the following modifications for maximum yield; the spin column was rinsed twice with $300 \mu \mathrm{L}$ of solution C4; and the DNA was eluted in $100 \mu \mathrm{L}$ of $10 \mathrm{mM}$ Tris. Total nucleic acid concentration and DNA purity were measured on a NanoDrop ${ }^{\circledR}$ ND-2000 UV-Vis Spectrophotometer (NanoDrop Technologies, Wilmington, DE, USA). 


\subsection{Pyrotag Sequencing, Phylogenetic Analysis and Statistics}

The methods used were identical to those described in [20]. Briefly, SSU rRNA amplicons were prepared using universal primers for the V6-V8 variable SSU rRNA region: 926f (5' AAACTYAAAKGAATTGRCGG 3') and 1392r (5' ACGGGCGGTGTGTRC 3') with adaptor and barcode, and sequenced at the Genome Quebec and McGill University Innovation Center (Montréal, QC, Canada) using a Roche GS-FLX Titanium Series sequencer. Pyrotag reads were filtered using quality control criteria (minimum length $200 \mathrm{bp}$, no ambiguous base reads, no missing quality scores, mean quality score greater than 25, no more than six nucleotide length homopolymer runs, and no mismatches in reverse primer) with the Qiime suite of Python scripts [24] as described in [20]. Operational taxonomic units (OTUs) were clustered according to $95 \%$ sequence similarity. OTUs represented by one read only (singletons) were excluded. For subsequent analyses all samples were rarefied (i.e., subsampled) to identical read counts equal to the lowest. Taxonomic summaries at the Order and Genus levels, as well as alpha- and beta-diversity analyses, were performed on the rarefied OTU table. Phylogenetic trees with pyrotag OTUs and nearest neighbors picked by using BLASTn to the NCBI nucleotide databases [62] were constructed by trimming the NCBI SSU rRNA sequences to the same region as the pyrotag amplicons and aligning these using MUSCLE version 3.8.31 [63] to the reverse complement of the pyrotag OTUs representative sequences followed by tree building with PHYML (nucleotide substitution model HKY, 100 bootstraps) [64]. Data visualization and statistical analyses were performed using packages (as stipulated in the caption of each figure) run in $\mathrm{R}$ version 3.1.2 (https://www.r-project.org/). To explore associations between different microbial groups, a correlation network was used to find co-occurring genus-level OTUs. Pearson product-moment correlations between pair-wise OTU read counts were computed on a filtered dataset that excluded rare OTUs (those represented by fewer than 15 reads) and OTUs that were present in fewer than 3 samples using the method of SparCC [65]. SparCC corrects relative abundance data for spurious correlations that arise due to low diversity samples in the sample set. Only those correlations that were statistically significant ( $p$-value $<0.01$ ) based on 100 bootstraps of shuffled read counts were included in the network. To reduce the complexity of the network, only highly-correlated OTUs, with Pearson correlation coefficients greater than 0.7 or less than -0.7 were considered.

\subsection{Quantitative Polymerase Chain Reaction}

Total bacteria SSU rRNA copies were quantified using quantitative polymerase chain reaction (qPCR) with primers BACT1369F (5' CGGTGAATACGTTCYCGG $3^{\prime}$ ) and BACT1492R (5' GGWTACCTTGTTACGACTT 3') [66,67]. Total reaction volume was $15 \mu \mathrm{L}$ with $1 \mu \mathrm{L}$ of each primer at a concentration of $5 \mathrm{mM}$ and $5 \mu \mathrm{L}$ template. The remaining volume consisted of SsoFast ${ }^{\mathrm{TM}}$ Evagreen $^{\circledR}$ supermix (BioRad, Hercules, CA, USA). Reaction conditions were $95^{\circ} \mathrm{C}$ for $3 \mathrm{~min}$ activation, followed by 40 cycles of denaturation at $95^{\circ} \mathrm{C}$ for $10 \mathrm{~s}$ and annealing/extension at $55^{\circ} \mathrm{C}$ for $10 \mathrm{~s}$. Reactions were carried out in Multiplate ${ }^{\mathrm{TM}}$ Low-Profile 96-well Unskirted PCR plates (BioRad MLL-9651) sealed with Microseal 'B' Adhesive seals (BioRad MSB-1001) in a BioRad CFX Connect Real-Time thermocycler. Standards were prepared from plasmid pCR4_16S_Bac_1 containing a purified PCR product from a laboratory culture. PCR products purified using the QIAquick PCR Purification Kit (Qiagen, Hilden, Germany) were sequenced using the Sanger method by the Nucleic Acid Protein Service (NAPS) unit at the University of British Columbia for confirmation of correct target. PCR products were cloned for expression in E. coli using the TOPO ${ }^{\circledR}$ TA Cloning ${ }^{\circledR}$ Kit with $\mathrm{PCR}^{\circledR} 2.1 \mathrm{TOPO}^{\circledR}$ (ThermoFisher Scientific, Waltham, MA, USA). Serial dilutions of standards were run together with the samples. For bacterial SSU rRNA quantification, standard concentrations ranged from $3 \times 10^{5}$ to $3 \times 10^{8}$ copies and the $R^{2}$ for fit of Cq numbers with $\log 10$ copies was 0.985). 


\section{Conclusions}

The composition of microbial populations within biosolids submerged in a BCR treating metal-rich leachate were fairly consistent over the seasons of one year despite shifts in temperature from 0 to $17^{\circ} \mathrm{C}$. Sulfate-reducers, key for successful metal treatment, did not appear to be inhibited by cold temperatures, and the sulfate-reducer-related taxa found in the biosolids were closely related to known psychrophilic or psychrotolerant sulfate-reducers suggesting that sulfate-reducers have the potential to adapt to cold temperatures. Relative abundance of taxa was not constant. Alternating temporal fluctuations were observed between fermentative taxa and consumers of fermentation by-products possibly indicative of the dynamics of supply and demand of carbon availability. Although temperature did not appear to influence the microbial population structure of the bioreactor, it is still expected to influence the metabolic kinetics. With the current rapid advances in omics technologies, future efforts in bioreactor monitoring will be able to measure expressed genes, proteins and even metabolites to measure microbial activity as well as structure. This will provide greater insight into the impacts of metabolic variability on BCR performance.

Supplementary Materials: The following are available online at www.mdpi.com/2075-163X/6/2/36/s1, Table S1: Water chemistry properties in the vicinity of the organics over the monitoring period (concentrations are in $\mathrm{mg} / \mathrm{L}$ ), Table S2: Pyrolysis characteristics of the organic matter, Figure S1: Rarefaction curves calculating diversity indices ((a) chao1 and (b) phylogenetic diversity (PD) using the whole tree) produced from the alpha_diversity.py script within Qiime. Curves are coloured according to month that the sample was collected in. Curves calculating higher diversity indices indicate that those samples consist of more diverse microbial populations (i.e., a greater number of different types of microorganisms), Figure S2: Relative abundance of predominant genus-level microbial taxa in each monthly sample (excluding Proteobacteria, which are shown in Figure S3). Dot area is proportional to log10 percentage of reads assigned to that genus, Figure S3: Genus-level taxonomic assignments to the top 30 most prevalent Proteobacteria genera. Dot area is proportional to $\log 10$ percentage of reads assigned to that, Figure S4: Detrended correspondence (DCA) plot of Bray-Curtis dissimilarities between microbial populations by month. Yellow circle with red boarder represents microbial population of a particular month. When two months are close to one another that means that they share very similar microbial populations. The texts in blue are predominant taxa, at the genus level, close to the months in which they are more enriched. Bray-Curtis dissimilarities were fit to a linear model of environmental variables: temperature $(T)$, dissolved oxygen $(\mathrm{DO})$, time, iron concentration $(\mathrm{Fe})$ and the ratio of pyrolysable carbon (PC) to total organic carbon (TOC). The green arrows represent the direction in which the variable increases. The length of the green vector represents the strength of the effect of that variable on the microbial population. The only statistically significant effect was time $(p<0.01)$, Figure S5: Network diagram of strongly correlated OTUs ( $>95 \%$ similarity) with Pearson correlation coefficients greater than 0.7 (solid lines) or less than -0.7 (dashed lines). Size of the vertices (OTUs) corresponds to the read count for that OTU. Vertices are colored according to the phylum that the OTU was classified in. Vertices are labelled according to the genus that they were classified in. Figure S6: Phylogenetic tree of sulfate-reducing bacteria-related OTUs and their closest cultured relatives. The length of the red bars corresponds to the number of reads in each OTU. This number is also given at the end of the bar. Grey circles on the dendrogram branches indicate bootstrap values equal to or greater than $75 \%$.

Acknowledgments: Genome British Columbia and the Natural Sciences and Engineering Research Council of Canada are acknowledged for funding the work described in this manuscript through grants (108ROC and CRDPJ-364, respectively) to Susan A Baldwin. Matt Pommer of NatureWorks and Jeanine Powell are thanked for their help with field sampling and chemical analysis. Marcus Taupp is acknowledged for his assistance with the initial laboratory sample processing.

Author Contributions: Susan A. Baldwin carried out the field and some laboratory work, performed all the data analysis and wrote the manuscript. Jon Taylor and Maryam Rezadehbashi prepared samples for analysis. Al Mattes conceived the initial experimental design and contributed to editing the manuscript.

Conflicts of Interest: The authors declare no conflict of interest.

\section{Abbreviations}

The following abbreviations are used in this manuscript:

$\begin{array}{ll}\text { BCR } & \text { Biochemical reactor } \\ \text { DO } & \text { Dissolved oxygen } \\ \text { Fe } & \text { Iron } \\ \text { HC } & \text { Hydrocarbons }\end{array}$




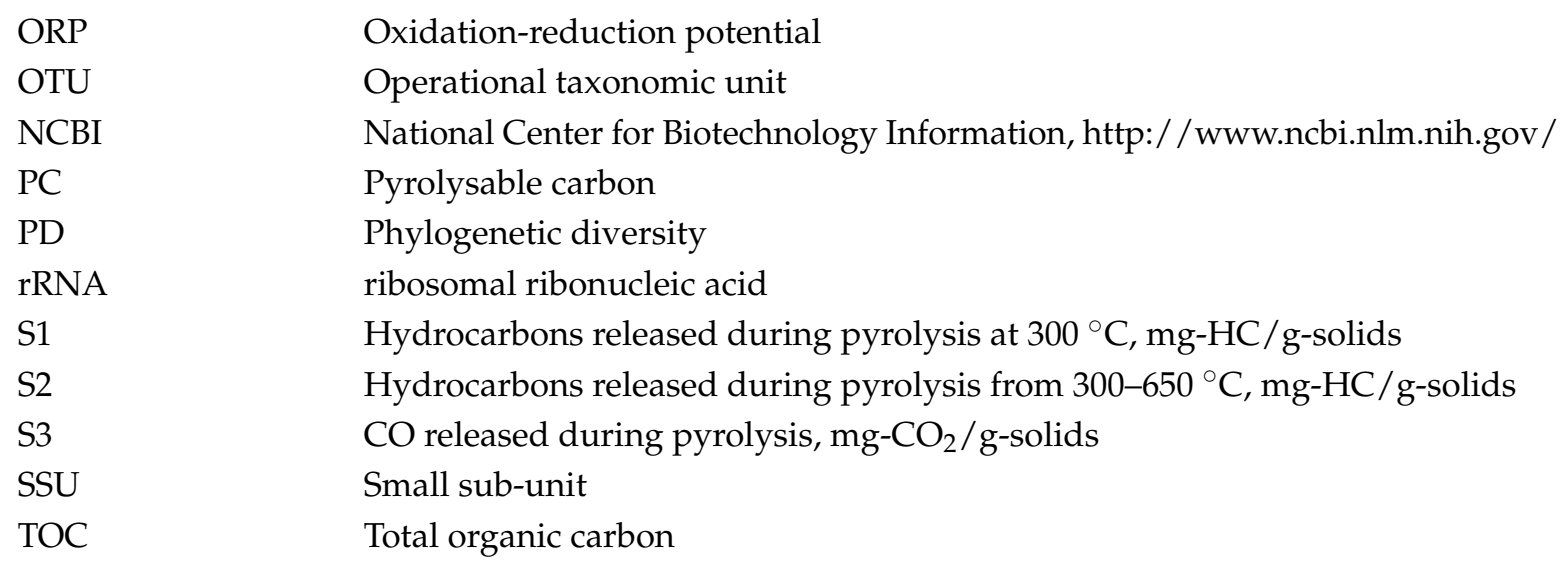

\section{References}

1. Zinck, J.; Griffith, W. Review of Mine Drainage Treatment and Sludge Management Operations; Natural Resources Canada Report CANMET-MMSL 10-058(CR). Natural Resources Canada: Ottawa, ON, Canada, 2013.

2. Gadd, G.M. Metals, minerals and microbes: Geomicrobiology and bioremediation. Microbiology 2010, 156, 609-643. [CrossRef] [PubMed]

3. Gusek, J.J. Passive Treatment 101: An overview of the technologies. In Proceedings of the U.S. EPA/National Groundwater Association's Remediation of Abandoned Mine Lands Conference, Denver, CO, USA, 2-3 October 2008; pp. 1-13.

4. Jalali, K.; Baldwin, S.A. The role of sulphate reducing bacteria in copper removal from aqueous sulphate solutions. Water Res. 2000, 34, 797-806. [CrossRef]

5. Ziemkiewicz, P.F.; Skousen, J.G.; Simmons, J. Long-term performance of passive acid mine drainage treatment systems. Mine Water Environ. 2003, 22, 118-129. [CrossRef]

6. Hiibel, S.R.; Pereyra, L.P.; Breazeal, M.V.R.; Reisman, D.J.; Reardon, K.F.; Pruden, A. Effect of organic substrate on the microbial community structure in pilot-scale sulfate-reducing biochemical reactors treating mine drainage. Environ. Eng. Sci. 2011, 28, 563-572. [CrossRef]

7. Hiibel, S.R.; Pereyra, L.P.; Inman, L.Y.; Tischer, A.; Reisman, D.J.; Reardon, K.F.; Pruden, A. Microbial community analysis of two field-scale sulfate-reducing bioreactors treating mine drainage. Environ. Microbiol. 2008, 10, 2087-2097. [CrossRef] [PubMed]

8. Edwards, K.J.; Gihring, T.M.; Banfield, J.F. Seasonal variations in microbial populations and environmental conditions in an extreme acid mine drainage environment. Appl. Environ. Microbiol. 1999, 65, 3627-3632. [PubMed]

9. Gilbert, J.A.; Steele, J.A.; Caporaso, J.G.; Steinbru, L.; Reeder, J.; Temperton, B.; Huse, S.; McHardy, A.C.; Knight, R.; Joint, I.; et al. Defining seasonal marine microbial community dynamics. ISME J. 2012, 6, $298-308$. [CrossRef] [PubMed]

10. Hwang, C.; Wu, W.; Gentry, T.J.; Carley, J.; Corbin, G.A.; Carroll, S.L.; Watson, D.B.; Jardine, P.M.; Zhou, J.; Criddle, C.S.; et al. Bacterial community succession during in situ uranium bioremediation: Spatial similarities along controlled flow paths. ISME J. 2009, 3, 47-64. [CrossRef] [PubMed]

11. Werker, A.G.; Dougherty, J.M.; McHenry, J.L.; Van Loon, W.A. Treatment variability for wetland wastewater treatment design in cold climates. Ecol. Eng. 2002, 19, 1-11. [CrossRef]

12. Stein, O.R.; Borden-Stewart, D.J.; Hook, P.B.; Jones, W.L. Seasonal influence on sulfate reduction and zinc sequestration in subsurface treatment wetlands. Water Res. 2007, 41, 3440-3448. [CrossRef] [PubMed]

13. Purdy, K.J.; Nedwell, D.B.; Embley, T.M. Analysis of the sulfate-reducing bacterial and methanogenic archaeal populations in contrasting Antarctic sediments. Appl. Environ. Microbiol. 2003, 69, 3181-3191. [CrossRef] [PubMed]

14. Sawicka, J.E.; Jørgensen, B.B.; Brüchert, V. Temperature characteristics of bacterial sulfate reduction in continental shelf and slope sediments. Biogeosciences 2012, 9, 3425-3435. [CrossRef] 
15. Knoblauch, C.; Sahm, K.; Jorgensen, B.B. Psychrophilic sulfate-reducing bacteria isolated from permanently cold Arctic marine sediments: Description of Desulfofrigus oceanense gen. nov., sp. nov., Desulfofrigus fragile sp. nov., Desulfofaba gelida gen. nov., sp. nov., Desulfotalea psychrophila gen. nov., sp. nov. and Desulfotalea arctica sp. nov. Int. J. Syst. Evol. Bacteriol. 1999, 49, 1631-1643.

16. Knoblauch, C.; Jorgensen, B.B. Effect of temperature on sulphate reduction, growth rate and growth yield in five psychrophilic sulphate-reducing bacteria from Arctic sediments. Environ. Microbiol. 1999, 1, 457-467. [CrossRef] [PubMed]

17. Abdollahi, H.; Nedwell, D.B. Seasonal temperature as a factor influencing bacterial sulfate reduction in a saltmarsh sediment. Microb. Ecol. 1979, 5, 73-79. [CrossRef] [PubMed]

18. Robador, A.; Brüchert, V.; Jørgensen, B.B. The impact of temperature change on the activity and community composition of sulfate-reducing bacteria in arctic versus temperate marine sediments. Environ. Microbiol. 2009, 11, 1692-1703. [CrossRef] [PubMed]

19. Mattes, A.; Evans, L.J.; Gould, D.W.; Duncan, W.F.A.; Glasauer, S. The long term operation of a biologically based treatment system that removes As, $\mathrm{S}$ and $\mathrm{Zn}$ from industrial (smelter operation) landfill seepage. Appl. Geochem. 2011, 26, 1886-1896.

20. Baldwin, S.A.; Khoshnoodi, M.; Rezadehbashi, M.; Taupp, M.; Hallam, S.; Mattes, A.; Sanei, H. The microbial community of a passive biochemical reactor treating arsenic, zinc, and sulfate-rich seepage. Front. Bioeng. Biotechnol. 2015, 3. [CrossRef] [PubMed]

21. Khoshnoodi, M.; Dipple, G.; Baldwin, S. Mineralogical study of a biologically-based treatment system that removes arsenic, zinc and copper from landfill leachate. Minerals 2013, 3, 427-449. [CrossRef]

22. Carrie, J.; Sanei, H.; Stern, G. Standardisation of Rock-Eval pyrolysis for the analysis of recent sediments and soils. Org. Geochem. 2012, 46, 38-53. [CrossRef]

23. Chao, A. Nonparametric-estimation of the number of classes in a population. Scand. J. Stat. 1984, 11, $265-270$.

24. Caporaso, J.G.; Kuczynski, J.; Stombaugh, J.; Bittinger, K.; Bushman, F.D.; Costello, E.K.; Fierer, N.; Pena, A.G.; Goodrich, J.K.; Gordon, J.I.; et al. QIMME allows analysis of high-throughput community sequencing data. Nat. Methods 2010, 7, 335-336. [CrossRef] [PubMed]

25. Anderson, I.; Ulrich, L.E.; Lupa, B.; Susanti, D.; Porat, I.; Hooper, S.D.; Lykidis, A.; Sieprawska-Lupa, M.; Dharmarajan, L.; Goltsman, E. Genomic characterization of methanomicrobiales reveals three classes of methanogens. PLoS ONE 2009, 4, e5797. [CrossRef] [PubMed]

26. Corkrey, R.; McMeekin, T.A.; Bowman, J.P.; Ratkowsky, D.A.; Olley, J.; Ross, T. Protein thermodynamics can be predicted directly from biological growth rates. PLoS ONE 2014, 9, e96100. [CrossRef]

27. Long, R.A.; Azam, F. Antagonistic interactions among marine pelagic bacteria. Appl. Environ. Microbiol. 2001, 67, 4975-4983. [CrossRef] [PubMed]

28. Leschine, S.B. Cellulose degradation in anaerobic environments. Annu. Rev. Microbiol. 1995, 49, $399-426$. [CrossRef] [PubMed]

29. Wexler, H.M. Bacteroides: The good, the bad, and the nitty-gritty. Clin. Microbiol. Rev. 2007, 20, 593-621. [CrossRef] [PubMed]

30. Kolton, M.; Sela, N.; Elad, Y.; Cytryn, E. Comparative genomic analysis indicates that niche adaptation of terrestrial Flavobacteria is strongly linked to plant glycan metabolism. PLoS ONE 2013, 8, e76704. [CrossRef]

31. Ventura, M.; Canchaya, C.; Tauch, A.; Chandra, G.; Fitzgerald, G.F.; Chater, K.F.; van Sinderen, D. Genomics of Actinobacteria: Tracing the evolutionary history of an ancient phylum. Microbiol. Mol. Biol. Rev. 2007, 71, 495-548. [CrossRef] [PubMed]

32. Suen, G.; Weimer, P.J.; Stevenson, D.M.; Aylward, F.O.; Boyum, J.; Deneke, J.; Drinkwater, C.; Ivanova, N.N.; Mikhailova, N.; Chertkov, O.; et al. The complete genome sequence of Fibrobacter succinogenes $\mathrm{S} 85$ reveals a cellulolytic and metabolic specialist. PLoS ONE 2011, 6, e18814. [CrossRef] [PubMed]

33. Li, H.-R.; Yu, Y.; Luo, W.; Zeng, Y.-X. Marisediminicola antarctica gen. nov., sp. nov., an actinobacterium isolated from the Antarctic. Int. J. Syst. Evol. Microbiol. 2010, 60, 2535-2539. [CrossRef] [PubMed]

34. Hamada, M.; Ichikawa, N.; Oguchi, A.; Komaki, H.; Tamura, T.; Fujita, N. Draft genome sequences of eight type strains of the genus demequina. Genome Announc. 2015, 3, e00281-15. [CrossRef] [PubMed]

35. Simpson, A.J.G.; Reinach, F.C.; Arruda, P.; Abreu, F.A.; Acencio, M.; Alvarenga, R.; Alves, L.M.C.; Araya, J.E.; Baia, G.S.; Baptista, C.S.; et al. The genome sequence of the plant pathogen Xylella fastidiosa. The Xylella fastidiosa consortium of the organization for nucleotide sequencing and analysis. Nature 2000, 406, 151-159. [PubMed] 
36. Holmes, D.E.; Nevin, K.P.; Woodard, T.L.; Peacock, A. D.; Lovley, D.R. Prolixibacter bellariivorans gen. nov., sp. nov., a sugar-fermenting, psychrotolerant anaerobe of the phylum Bacteroidetes, isolated from a marine-sediment fuel cell. Int. J. Syst. Evol. Microbiol. 2007, 57, 701-707. [CrossRef] [PubMed]

37. Meehan, C.J.; Beiko, R.G. A phylogenomic view of ecological specialization in the Lachnospiraceae, a family of digestive tract-associated bacteria. Genome Biol. Evol. 2014, 6, 703-713. [CrossRef] [PubMed]

38. Chen, S.; Niu, L.; Zhang, Y. Saccharofermentans acetigenes gen. nov., sp. nov., an anaerobic bacterium isolated from sludge treating brewery wastewater. Int. J. Syst. Evol. Microbiol. 2010, 60, 2735-2738. [CrossRef] [PubMed]

39. Kudo, H.; Cheng, K-J.; Costerton, J.W. Interactions between Treponema bryantii and cellulolytic bacteria in the in vitro degradation of straw cellulose. Can. J. Microbiol. 1987, 33, 244-248. [CrossRef] [PubMed]

40. Schmidtova, J.; Baldwin, S.A. Correlation of bacterial communities supported by different organic materials with sulfate reduction in metal-rich landfill leachate. Water Res. 2011, 45, 1115-1128. [CrossRef] [PubMed]

41. Wang, J.; Shi, M.; Lu, H.; Wu, D.; Shao, M.-F.; Zhang, T.; Ekama, G.A.; van Loosdrecht, M.C.M.; Chen, G.-H. Microbial community of sulfate-reducing up-flow sludge bed in the $\mathrm{SANI}^{\circledR}$ process for saline sewage treatment. Appl. Microbiol. Biotechnol. 2011, 90, 2015-2025. [CrossRef] [PubMed]

42. Balch, W.E.; Schoberth, S.; Tanner, R.S.; Wolfe, R.S. Acetobacterium, a new genus of hydrogen-oxidizing, carbon dioxide-reducing, anaerobic bacteria. Int. J. Syst. Bacteriol. 1977, 27, 355-361. [CrossRef]

43. Mattes, T.E.; Alexander, A.K.; Richardson, P.M.; Munk, A.C.; Han, C.S.; Stothard, P.; Coleman, N.V. The genome of Polaromonas sp. strain JS666: Insights into the evolution of a hydrocarbon- and xenobiotic-degrading bacterium, and features of relevance to biotechnology. Appl. Environ. Microbiol. 2008, 74, 6405-6416. [CrossRef] [PubMed]

44. Masuda, H.; Shiwa, Y.; Yoshikawa, H.; Zylstra, G.J. Draft genome sequence of the versatile alkane-degrading bacterium Aquabacterium sp. strain NJ1. Genome Announc. 2014, 2. [CrossRef] [PubMed]

45. Huang, Y.; Li, H.; Rensing, C.; Zhao, K.; Johnstone, L.; Wang, G. Genome sequence of the facultative anaerobic arsenite-oxidizing and nitrate-reducing bacterium Acidovorax sp. strain NO1. J. Bacteriol. 2012, 194, 1635-1636. [CrossRef] [PubMed]

46. Teng, Y.; Wang, X.; Li, L.; Li, Z.; Luo, Y. Rhizobia and their bio-partners as novel drivers for functional remediation in contaminated soils. Front. Plant Sci. 2015, 6. [CrossRef] [PubMed]

47. Nierman, W.C.; Feldblyum, T.V.; Laub, M.T.; Paulsen, I.T.; Nelson, K.E.; Eisen, J.; Heidelberg, J.F.; Alley, M.R.K.; Ohta, N.; Maddock, J.R.; et al. Complete genome sequence of Caulobacter crescentus. Proc. Natl. Acad. Sci. USA 2001, 98, 4136-4141. [CrossRef] [PubMed]

48. Wei, S.; Cui, H.; Jiang, Z.; Liu, H.; He, H.; Fang, N. Biomineralization processes of calcite induced by bacteria isolated from marine sediments. Braz. J. Microbiol. 2015, 46, 455-464. [CrossRef] [PubMed]

49. Pecheritsyna, S.A.; Rivkina, E.M.; Akimov, V.N.; Shcherbakova, V.A. Desulfovibrio arcticus sp. nov., a psychrotolerant sulfate-reducing bacterium from a cryopeg. Int. J. Syst. Evol. Microbiol. 2012, 62, 33-37. [CrossRef] [PubMed]

50. DeSantis, T.Z.; Hugenholtz, P.; Larsen, N.; Rojas, M.; Brodie, E.L.; Keller, K.; Huber, T.; Dalevi, D.; Hu, P.; Andersen, G.L. Greengenes, a chimera-checked $16 \mathrm{~S}$ rRNA gene database and workbench compatible with ARB. Appl. Environ. Microbiol. 2006, 72, 5069-5072. [CrossRef] [PubMed]

51. Kaksonen, A.H.; Plumb, J.J.; Robertson, W.J.; Spring, S.; Schumann, P.; Franzmann, P.D.; Puhakka, J.A. Novel thermophilic sulfate-reducing bacteria from a geothermally active underground mine in Japan. Appl. Environ. Microbiol. 2006, 72, 3759-3762. [CrossRef] [PubMed]

52. Karsten, S.; Jørgensen, B.B. Sulphate Reduction in Marine Sediments. In Marine Geochemistry; Schulz, H.D., Zabel, M., Eds.; Springer: Berlin, Germany, 2000; pp. 263-2812.

53. Rui, J.; Li, J.; Zhang, S.; Yan, X.; Wang, Y.; Li, X. The core populations and co-occurrence patterns of prokaryotic communities in household biogas digesters. Biotechnol. Biofuels 2015, 8, 158. [CrossRef] [PubMed]

54. Dollhopf, S.L.; Pariseau, M.L.; Hashsham, S.A.; Tiedje, J.M. Competitive and cooperative interactions affecting a fermentative spirochete in anaerobic chemostats. Microb. Ecol. 2003, 46, 1-11. [CrossRef] [PubMed]

55. Rohini-Kumar, M.; Saravanan, V.S. Candidate OP phyla: Importance, ecology and cultivation prospects. Indian J. Microbiol. 2010, 50, 474-477. [CrossRef] [PubMed] 
56. Wrighton, K.C.; Thomas, B.C.; Sharon, I.; Miller, C.S.; Castelle, C.J.; VerBerkmoes, N.C.; Wilkins, M.J.; Hettich, R.L.; Lipton, M.S.; Williams, K.H.; et al. Fermentation, hydrogen, and sulfur metabolism in multiple uncultivated bacterial phyla. Science 2012, 337, 1661-1665. [CrossRef] [PubMed]

57. Hibbing, M.E.; Fuqua, C.; Parsek, M.R.; Peterson, S.B. Bacterial competition: Surviving and thriving in the microbial jungle. Nat. Rev. Microbiol. 2010, 8, 15-25. [CrossRef] [PubMed]

58. Mielczarek, A.T.; Kragelund, C.; Eriksen, P.S.; Nielsen, P.H. Population dynamics of filamentous bacteria in Danish wastewater treatment plants with nutrient removal. Water Res. 2012, 46, 3781-3795. [CrossRef] [PubMed]

59. Eaton, A.D.; Clesceri, L.S.; Rice, E.W.; Greenberg, A.E. Standard Methods for the Examination of Water and Wastewater; American Public Health Association: Washington, DC, USA, 2005.

60. Verdouw, H.; van Echteld, C.J.A.; Dekkers, E.M.J. Ammonia determination based on indophenol formation with sodium salicylate. Water Res. 1978, 12, 399-402. [CrossRef]

61. Behar, F.; Beaumont, V.; Penteado, H.D.B. Rock-Eval 6 technology: Performances and developments. Oil Gas Sci. Technol. 2001, 56, 111-134. [CrossRef]

62. Pruitt, K.D.; Tatusova, T.; Klimke, W.; Maglott, D.R. NCBI reference sequences: Current status, policy and new initiatives. Nucleic Acids Res. 2009, 37, D32-D36. [CrossRef] [PubMed]

63. Edgar, R.C. MUSCLE: Multiple sequence alignment with high accuracy and high throughput. Nucleic Acids Res. 2004, 32, 1792-1797. [CrossRef] [PubMed]

64. Guindon, S.; Delsuc, F.; Dufayard, J.-F.; Gascuel, O. Estimating maximum likelihood phylogenies with PhyML. Methods Mol. Biol. 2009, 537, 113-137. [PubMed]

65. Friedman, J.; Alm, E.J. Inferring correlation networks from genomic survey data. PLoS Comput. Biol. 2012, 8, e1002687. [CrossRef] [PubMed]

66. Suzuki, M.T.; Taylor, L.T.; DeLong, E.F. Quantitative analysis of small-subunit rRNA genes in mixed microbial Populations via 5'-nuclease assays. Appl. Environ. Microbiol. 2000, 66, 4605-4614. [CrossRef] [PubMed]

67. Vigneron, A.; Cruaud, P.; Pignet, P.; Caprais, J.-C.; Cambon-Bonavita, M.-A.; Godfroy, A.; Toffin, L. Archaeal and anaerobic methane oxidizer communities in the Sonora Margin cold seeps, Guaymas Basin (Gulf of California). ISME J. 2013, 7, 1595-1608. [CrossRef] [PubMed]

(C) 2016 by the authors; licensee MDPI, Basel, Switzerland. This article is an open access article distributed under the terms and conditions of the Creative Commons Attribution (CC-BY) license (http://creativecommons.org/licenses/by/4.0/). 